\title{
Cigarette-related cadmium and environmental pollution exposure are reflected in airway ultrafine particle content
}

\author{
Einat Fireman Klein ${ }^{1,2,4}$, Yochai Adir ${ }^{1,4}$, Elizabeth Fireman ${ }^{5,6}$ and \\ Aharon Kessel $\mathrm{K}^{3,4}$
}

Affiliations: ${ }^{1}$ Pulmonary Division, Carmel Medical Center, Haifa, Israel. ${ }^{2}$ Dept of Internal Medicine B, BnaiZion Medical Center, Haifa, Israel. ${ }^{3}$ Division of Allergy and Clinical Immunology, Bnai-Zion Medical Center, Haifa, Israel. ${ }^{4}$ Affiliated with the Rappaport Faculty of Medicine, Technion - Institute of Technology, Haifa, Israel. ${ }^{4}$ The Institute of Pulmonary Diseases, National Laboratory Service for ILD, Tel Aviv Sourasky Medical Center, Tel Aviv, Israel. ${ }^{5}$ Dept of Occupational and Environmental Medicine Sackler School of Medicine, Tel Aviv University, Tel Aviv, Israel.

Correspondence: Einat Fireman Klein, Carmel Medical Center, 7 Michal St, Haifa, 3436212, Israel. E-mail: einatfiredgmail.com

\section{ABSTRACT}

Introduction: Particulate matter (PM) and cigarette-related cadmium exposure increases inflammation and smokers' susceptibility to developing lung diseases. The majority of inhaled metals are attached to the surface of ultrafine particles (UFPs). A low inhaled UFP content in exhaled breath condensate (EBC) reflects a high inflammatory status of airways.

Methods: EBC was collected from 58 COPD patients and 40 healthy smokers and nonsmokers. Participants underwent spirometry, diffusion capacity, EBC and blood sampling. Environmental pollution data were collected from monitoring stations. UFPs were measured in EBC and serum, and cadmium content was quantified.

Results: Subjects with low UFP concentrations in EBC $\left(<0.18 \times 10^{8} \cdot \mathrm{mL}^{-1}\right)$ had been exposed to higher long-term $\mathrm{PM}_{2.5}$ levels versus subjects with high UFP concentrations in EBC $\left(>0.18 \times 10^{8} \cdot \mathrm{mL}^{-1}\right)$ (21.9 $\mu \mathrm{g} \cdot \mathrm{m}^{-3}$ versus $\left.17.4 \mu \mathrm{g} \cdot \mathrm{m}^{-3}, \mathrm{p} \leqslant 0.001\right)$. Long-term $\mathrm{PM}_{2.5}$ exposure levels correlated negatively with UFP concentrations in EBC and positively with UFP concentrations in serum $(\mathrm{r}=-0.54, \mathrm{p} \leqslant 0.001$ and $\mathrm{r}=0.23, \mathrm{p}=0.04$, respectively). Healthy smokers had higher cadmium levels in EBC versus healthy nonsmokers and COPD patients $(25.2 \mathrm{ppm}$ versus $23.7 \mathrm{ppm}$ and $23.3 \mathrm{ppm}, \mathrm{p}=0.02$ and $\mathrm{p}=0.002$, respectively). Subjects with low UFP concentrations in EBC also had low cadmium levels in EBC versus subjects with high UFP levels (22.8 ppm versus $24.2 \mathrm{ppm}, \mathrm{p}=0.004)$

Conclusions: Low UFP concentration in EBC is an indicator of high-level PM exposure. High cadmium levels in EBC among smokers and the association between cadmium and UFP content in EBC among COPD patients indicate cadmium lung toxicity.

@ERSpublications

Low UFP concentration in EBC may be a combined marker of high-level PM exposure and airway inflammation. Relation between Cd and UFP content in COPD-EBC may reveal the high level of penetration of $\mathrm{Cd}$ and its association to lung toxicity. https://bit.ly/2YOfOKO

Cite this article as: Fireman Klein E, Adir Y, Fireman E, et al. Cigarette-related cadmium and environmental pollution exposure are reflected in airway ultrafine particle content. ERJ Open Res 2020; 6: 00361-2019 [https://doi.org/10.1183/23120541.00361-2019].

Received: 7 Jan 2020 | Accepted after revision: 15 June 2020

Copyright $\odot$ ERS 2020. This article is open access and distributed under the terms of the Creative Commons Attribution Non-Commercial Licence 4.0. 


\section{Introduction}

Particulate matter (PM) in ambient air pollution continues to be a pressing issue in the global public health agenda. The vast majority of the world's population is exposed to outdoor pollution that exceeds World Health Organization (WHO) air quality guidelines [1]. An association between exposure to fine $\mathrm{PM}\left(\mathrm{PM}_{2.5}\right)$ to an increase in all-cause mortality was demonstrated, even when the level of exposure was below the US national standard level [2]. A recent study has shown that perinatal exposure to ultrafine particles (UFPs) is related to an increased incidence of childhood asthma [3]. The association between chronic exposure to PM and an increased risk of developing cardiovascular and respiratory diseases is well established [4]. Most of these data are supported by large-scale epidemiological studies [2, 5, 6] with several randomised controls trials having demonstrated a relation between PM exposure and negative cardiopulmonary effects $[7,8]$. There are few individual-level studies that take into consideration cofactors, such as residential pollution exposures, a person's mobility during the day and comorbidities, when reporting on PM health effects. Patients with COPD were described as an example of a subpopulation with increased mortality rates due to ambient air pollution exposure [9]. Biological monitoring, which includes the most health-relevant assessments of human exposure to environmental pollutants, is a direct measurement of a given substance and its metabolites. Many components of the human exposome can be measured in several biological samples, such as blood, sputum and exhaled breath condensate (EBC). Occupational exposure to inhaled toxic chemicals, such as beryllium, chromium, silica and lead, can be detected and monitored using induced sputum and EBC techniques [10-13]. UFPs in EBC were reported to reflect airway inflammation levels and serve as a novel marker of exacerbation risk in COPD [14]. Moreover, a major toxic effect of inhaled UFP is related to their large surface area, which enables transmission and absorption of hazardous materials, such as heavy metals [15].

Heavy metals in tobacco smoke have a significant role in cigarette-related diseases, and cigarette smoking is well recognised as a major component of COPD patients' exposome. Although their amounts are small in a single cigarette, minute particles of these metals accumulate in the body over years of exposure [16]. The toxic heavy metal particles that are present in tobacco smoke include cadmium, lead, arsenic, chromium and nickel. While the other metals have several other sources, the single-most important source of cadmium is tobacco smoke [17]. We had earlier shown increased epithelial permeability, as reflected in low concentrations of UFP in EBC, that was due to the inflammatory state of airways [14]. Our next step was to evaluate the cigarette smoke-related heavy metal content in EBC in the same population of COPD patients.

\section{Materials and methods \\ Study population}

The participants were 58 COPD patients (study group) and 40 healthy smokers and nonsmokers (controls). They were all recruited in a small district in the northern Israeli city of Haifa.

Demographic characteristics of the study population are presented in table 1 . The patients had a mean $\pm S D$ age of $68.3 \pm 8.6$ years, forced expiratory volume in $1 \mathrm{~s}\left(\mathrm{FEV}_{1}\right) 54 \pm 15.9 \%$ predicted, a COPD assessment test (CAT) score of $14 \pm 10$ and a total of $1.6 \pm 1.4$ exacerbations per year, $46(79 \%)$ were males and $10(17 \%)$ were current smokers. The study group consisted of outpatients of the Center for Treatment of Lung

\section{TABLE 1 Demographic and clinical characteristics of the study population ( $\mathrm{n=98}$ )}

\begin{tabular}{|c|c|c|c|}
\hline & COPD patients $(n=58)$ & Healthy subjects $(n=40)$ & p-value \\
\hline Age years & $68.3 \pm 8.6$ & $57.2 \pm 14.4$ & 0.001 \\
\hline Male & $46(79)$ & $21(52.5)$ & 0.05 \\
\hline Smoking & & & $<0.001$ \\
\hline Active & $10(17)$ & 13 (32.5) & \\
\hline Former $^{\#}$ & $46(79)$ & $10(25)$ & \\
\hline Never & $2(3)$ & $17(42.5)$ & \\
\hline Smoking history pack-years & $59.3 \pm 38.2$ & $13.6 \pm 20.5$ & $<0.001$ \\
\hline Occupational exposure & $31(53)$ & $17(42.5)$ & 0.28 \\
\hline Distance from monitoring station $\mathrm{km}$ & $3.1 \pm 2.9$ & $3.9 \pm 2.4$ & 0.15 \\
\hline \multicolumn{4}{|c|}{$\begin{array}{l}\text { Data are presented as mean } \pm \text { SD or } n(\%) \text {, unless otherwise stated. \#: A subject with a } \geqslant 20 \text { pack-year } \\
\text { history and self-reported "former smoker"; ": Occupational exposure to cleaning detergent, dye, asbestos, } \\
\text { dust, fuel, sawdust, nitrogen acid, acetone, flour, sand, glue, smoke, heavy metals welding, plastic and/or } \\
\text { coal. A minimum of } 1 \text { year of exposure was taken as positive. Reproduced from [14], with permission from } \\
\text { the publisher. }\end{array}$} \\
\hline
\end{tabular}


Diseases ("Hagefen Clinic") of Carmel Medical Center, and they were all clinically stable during the study period. None had experienced any exacerbation of their COPD within the previous 4 weeks. The control group included smokers and nonsmokers who were hospitalised patients and volunteers from the healthcare staff of Bnai-Zion Medical Center. Patients with chronic lung disease or those who had been hospitalised for any infectious or inflammatory conditions were excluded. All study participants filled in a demographic and clinical questionnaire, and the study group patients also filled in the CAT. All subjects underwent spirometry, diffusion capacity testing, EBC testing and blood sampling. They were all asked to avoid smoking and the use of any type of inhaled medication prior to EBC collection, as recommended by EBC guidelines [18].

The study was approved by the Helsinki committees of the Bnai-Zion and Carmel Medical Centers (nos. 0051-14-BNZ and 0137-14-CMC, respectively), and all subjects signed their informed consent to participate.

\section{EBC sample collection}

A portable condenser (TURBODECCS, ItalChill, Parma, Italy) was used as described in detail elsewhere [14]. Briefly, subjects breathed into a collecting system for $5 \mathrm{~min}$ at normal tidal volume. Samples were stored at $-80^{\circ} \mathrm{C}$ until analysis. All EBC collections were performed in an environment with room temperature $\left(22-23{ }^{\circ} \mathrm{C}\right)$ and humidity $(50 \%)$ controlled by a closed air conditioning system.

\section{Pulmonary function tests}

A Masterlab spirometer (Masterlab E, Jaeger, Wurzburg, Germany) was used to perform the pulmonary function tests. Measurements were carried out according to standard protocols of the American Thoracic Society guidelines [19].

\section{Peripheral blood samples}

Blood samples were drawn by conventional methods and analysed for complete blood count, C-reactive protein (CRP), bilirubin and lactate dehydrogenase $(\mathrm{LDH})$ in the haematology and chemistry laboratories of the Bnai-Zion Medical Center.

\section{Questionnaire}

We used a demographic, occupational and health data self-reported questionnaire. The questionnaire was validated by the Epidemiological and Preventive Medicine Department in the Tel Aviv University School of Public Health. The CAT score was used to assess disease-related symptoms [20]. Exacerbation history of COPD patients during the past year was taken from medical records. "Exacerbation" was defined by the patient's having been hospitalised due to COPD exacerbation/pneumonia or treated as an outpatient with prednisone plus antibiotics due to worsening of respiratory symptoms.

\section{UFP measurement and analysis in biological samples}

The size and concentration of the particles was assessed in EBC and serum samples with the NanoSight LM20 system (NanoSight Ltd., Salisbury, UK) [14]. Briefly, the Brownian motion of particles in the range of 10-1000 nm was captured by the camera. Nanoparticle Tracking Analysis software (version 2.0) calculated their size according to the particles' motion speed. A UFP concentration of $\leqslant 0.18 \times 10^{8} \cdot \mathrm{mL}^{-1}$ in EBC samples was taken as being low. That cut-off had been earlier found to be related to disease activity among COPD patients [14].

\section{Environmental ambient air pollution data}

PM levels were collected from the Israeli Ministry of Environmental Protection's online database (www. sviva.gov.il/English/Pages/HomePage.aspx). Data on PM levels were collected from 17 general and transportation monitoring stations located in a land area of $1000 \mathrm{~km}^{2}$ in the northern part of Israel. The general stations are located at roof height in representative areas, which are not adjacent to specific emission sources, such as industrial plants. Transportation stations are located at pavement height near primary traffic junctions. All monitoring stations are run by the Ministry of Environmental Protection and by the Israel Electric Corporation. Concentrations of $\mathrm{PM}$ air pollution $\left(\mathrm{PM}_{2.5}\right.$ and $\left.\mathrm{PM}_{10}\right)$ were collected from monitoring stations between September 2015 and October 2016. Average values of the data retrieved from the monitor station closest to each subject's home address were calculated for a duration of 3 days (short-term exposure) and 3 months (long-term exposure) preceding the performance of EBC. The relevant monitoring station for each subject was located within a radius of $11 \mathrm{~km}$ from their residential area, since this reportedly represents the radius most sensitive to environmental changes [21]. The average distance from the monitoring station was $3.4 \pm 2.7 \mathrm{~km}$. 
Quantification of cigarette smoke-related heavy metal content in EBC samples

We used a Niton XL3 X-ray fluorescence (XRF) spectrometer analyser (Thermo Fisher Scientific, Germany) to quantify cigarette-smoke-related heavy metal content in EBC samples. XRF analysers determined the presence and quantity of cadmium, lead, arsenic, chromium and nickel in EBC samples by measuring the specific fluorescent X-ray emitted from the sample when excited by a primary X-ray source. Each sample was scanned twice in different areas and the average of two repeated measurements was calculated. For an element to be detected by the analyser, the measured EBC concentration had to be at least three times the SD of the measurement.

\section{Statistical analysis}

Statistical analyses were performed using the SPSS software version 24.0 for Windows (SPSS). Differences between PM epidemiological and biological monitoring levels and other parameters were compared by the t-test and the one-way ANOVA test, and they were considered significant at values $<0.05$. Spearman's coefficients were used to correlate the epidemiological PM exposure level with clinical parameters and UFP concentrations in biological samples.

Sample size was calculated to detect a mean difference of $0.2(\Delta \mathrm{Me}=0.2)$ between UFP-EBC concentration of COPD patients and healthy nonsmoker subjects, according to $5 \% \alpha$ and $80 \%$ power. In a pilot study conducted on the first 20 subjects recruited, SD for the COPD group was 0.09 and SD for the healthy nonsmoker group was 0.28 . Based on these values, 17 subjects should be included in each group to detect a mean difference of $0.2(\Delta \mathrm{Me}=0.2)$ in UFP-EBC concentration between the groups. Sample size included 17 healthy smokers and we added 23 healthy past and active smokers to evaluate the smoking effect. As for the COPD group, sample size was increased to 58 patients $(n=58)$ to boost the statistical power of the test, as COPD is a heterogenous disease in terms of phenotypes.

\section{Results}

A total of 98 subjects were recruited, including 58 COPD patients with different levels of disease severity and 40 healthy smokers and nonsmokers (controls). Demographic and clinical characteristics of the study population are presented in tables 1 and 2. The samples were collected from 17 environmental monitoring stations, and the average $\mathrm{PM}_{2.5}$ and $\mathrm{PM}_{10}$ exposure doses were $16.1 \mu \mathrm{g} \cdot \mathrm{m}^{-3}$ and $41.3 \mu \mathrm{g} \cdot \mathrm{m}^{-3}$ for short-term exposure and $18.8 \mu \mathrm{g} \cdot \mathrm{m}^{-3}$ and $53.9 \mu \mathrm{g} \cdot \mathrm{m}^{-3}$ for long-term exposure, respectively.

Firstly, we integrated environment monitoring data with clinical parameters and systemic inflammation markers. Forced expiratory volume in $1 \mathrm{~s}\left(\mathrm{FEV}_{1}\right)$ and diffusing lung capacity for carbon monoxide $\left(D_{\mathrm{LCO}}\right)$ levels correlated negatively with long-term PM2.5 exposure levels ( $\mathrm{p} \leqslant 0.001$ and $\mathrm{p}=0.05$, respectively). There was also a positive correlation between long-term $\mathrm{PM}_{2.5}$ exposure levels and the levels of the systemic inflammation markers CRP and $\mathrm{LDH}$ in serum $(\mathrm{p}=0.01$ and $\mathrm{p}=0.02$, respectively) (table 3 ). We then focused on COPD patients, as they are more vulnerable to ambient air pollution compared to the healthy population. Addressing PM exposure and induced inflammation in COPD, we have found that patients with a CRP $\geqslant 5 \mathrm{mg} \cdot \mathrm{L}^{-1}$ were exposed to significantly higher levels of $\mathrm{PM}_{2.5}$ in the short term compared to patients with a CRP $<5 \mathrm{mg} \cdot \mathrm{L}^{-1}\left(19.5 \mu \mathrm{g} \cdot \mathrm{m}^{-3}\right.$ versus $\left.15.1 \mu \mathrm{g} \cdot \mathrm{m}^{-3}, \mathrm{p}=0.05\right)$ (figure 1$)$. We further questioned the impact of PM exposure on COPD prevalence. COPD patients were exposed to higher levels of long-term $\mathrm{PM}_{2.5}$ and $\mathrm{PM}_{10}$ compared to healthy controls $\left(20.9 \mu \mathrm{g} \cdot \mathrm{m}^{-3}\right.$ versus $16.1 \mu \mathrm{g} \cdot \mathrm{m}^{-3}$ and $50.8 \mu \mathrm{g} \cdot \mathrm{m}^{-3}$ versus $43.2 \mu \mathrm{g} \cdot \mathrm{m}^{-3}, \mathrm{p} \leqslant 0.001$ and $\mathrm{p} \leqslant 0.001$, respectively) (figure 2 ). There was no significant difference in environmental stations' distribution between COPD patients and the healthy

\section{TABLE 2 Pulmonary function and blood tests of the study and control groups (n=98)}

\begin{tabular}{|c|c|c|c|}
\hline & COPD patients $(n=58)$ & Healthy subjects $(n=40)$ & p-value \\
\hline FEV $_{1} \%$ pred & $54 \pm 15.9$ & $93 \pm 17.5$ & $<0.001$ \\
\hline$D_{\text {Lco }} \%$ pred & $66.6 \pm 25.6$ & $78.5 \pm 12.4$ & 0.008 \\
\hline WBC $\times 1000 \cdot \mathrm{mm}^{-3}$ & $8.3 \pm 1.7$ & $7.3 \pm 2.4$ & 0.02 \\
\hline EOS abs cells $\mathrm{mm}^{-3}$ & $224 \pm 163$ & $154 \pm 97$ & 0.009 \\
\hline CRP $\mathrm{mg} \cdot \mathrm{L}^{-1}$ & $5 \pm 6.4$ & $3 \pm 3.1$ & 0.05 \\
\hline LDH U. $\mathrm{L}^{-1}$ & $391 \pm 93.1$ & $330 \pm 82.2$ & 0.004 \\
\hline \multicolumn{4}{|c|}{$\begin{array}{l}\text { Data are presented as mean } \pm \mathrm{SD} \text {. } \mathrm{FEV}_{1} \text { : forced expiratory volume in } 1 \mathrm{~s} ; \% \text { pred: } \% \text { predicted; } D_{\mathrm{LCO}} \\
\text { diffusing lung capacity for carbon monoxide; WBC: white blood cell; EOS abs: eosinophil absolute count; } \\
\text { CRP: C-reactive protein; } \mathrm{LDH} \text { : lactate dehydrogenase. Reproduced from [14], with permission from the } \\
\text { publisher. }\end{array}$} \\
\hline
\end{tabular}




\begin{tabular}{|c|c|c|c|c|c|c|}
\hline & $\begin{array}{l}\text { UFP in EBC } \\
\times 10^{8} \cdot \mathrm{mL}^{-1}\end{array}$ & $\begin{array}{l}\text { UFP in serum } \\
\times 10^{8} \cdot \mathrm{mL}^{-1}\end{array}$ & $\begin{array}{l}\mathrm{FEV}_{1} \% \\
\text { pred }\end{array}$ & $\begin{array}{l}D_{\text {Lco }} \% \\
\text { pred }\end{array}$ & $\begin{array}{c}\text { CRP } \\
\mathrm{mg} \cdot \mathrm{L}^{-1}\end{array}$ & $\begin{array}{l}\text { LDH } \\
\mathrm{U} \cdot \mathrm{L}^{-1}\end{array}$ \\
\hline $\begin{array}{c}\mathrm{PM}_{2.5} \text { (3 months } \\
\text { of exposure) }\end{array}$ & $r=-0.54^{* * *}$ & $r=0.23^{*}$ & $r=-0.46 * * *$ & $r=-0.23^{*}$ & $r=0.3^{* *}$ & $r=0.3^{*}$ \\
\hline
\end{tabular}

$\mathrm{PM}_{2.5}$ : particulate matter $<2.5 \mu \mathrm{m}$; EBC: exhaled breath condensate; UFP: ultrafine particles; $\mathrm{FEV}_{1}$ : forced expiratory volume in $1 \mathrm{~s} ; \%$ pred: \% predicted; $D_{\text {LCO }}$ : diffusing lung capacity for carbon monoxide; CRP: C-reactive protein; LDH: lactate dehydrogenase. *: $p \leqslant 0.05 ;{ }^{* *}: p \leqslant 0.01 ;{ }^{* *}: p<0.001$.

controls (Chi-squared $(17)=19, \mathrm{p}=0.3)$. Smoking status was not a confounding factor, as there were no differences in PM exposure levels between healthy smokers and healthy nonsmokers. These results were adjusted to sex and age.

The above-presented results reflect the traditional environmental assessments of exposure that do not reflect the exposure at personal levels. There is an urgent need, especially in chronic diseases, to explore exposure using biological monitoring.

In this context the first step was to correlate both measurements, environmental PM monitoring and UFPs in biological samples, EBC and serum. Our purpose was to understand how much the particles retrieved by biological monitoring are related to particles from the environment.

It emerged that subjects with low concentrations of UFPs in EBC $\left(<0.18 \times 10^{8} \cdot \mathrm{mL}^{-1}\right)$ had been exposed to high levels of long-term $\mathrm{PM}_{10}$ and $\mathrm{PM}_{2.5}$ compared to subjects with high concentrations of UFPs in EBC $\left(65 \mu \mathrm{g} \cdot \mathrm{m}^{-3}\right.$ versus $49.1 \mu \mathrm{g} \cdot \mathrm{m}^{-3}$ and $21.9 \mu \mathrm{g} \cdot \mathrm{m}^{-3}$ versus $17.4 \mu \mathrm{g} \cdot \mathrm{m}^{-3}, \mathrm{p} \leqslant 0.001$ and $\mathrm{p}=0.007$, respectively, figure $3 \mathrm{a}$ and $\mathrm{b}$ ). In addition, long-term $\mathrm{PM}_{2.5}$ exposure levels correlated negatively with the concentrations of UFPs in EBC and positively with the concentrations of UFPs in serum $(\mathrm{p} \leqslant 0.001$ and $\mathrm{p}=0.04$, respectively) (table 3 ).

Lifestyle (i.e. smoking) is considered to be an important contributor of the exposome which integrates internal and external exposures. Cigarette smoking is a major component of UFPs in COPD patients' airways. Our further rationale was that measuring the metal content in the EBC will enable us to identify at least the most prevalent heavy metals found in tobacco smoke. In fact we were able to detect high levels

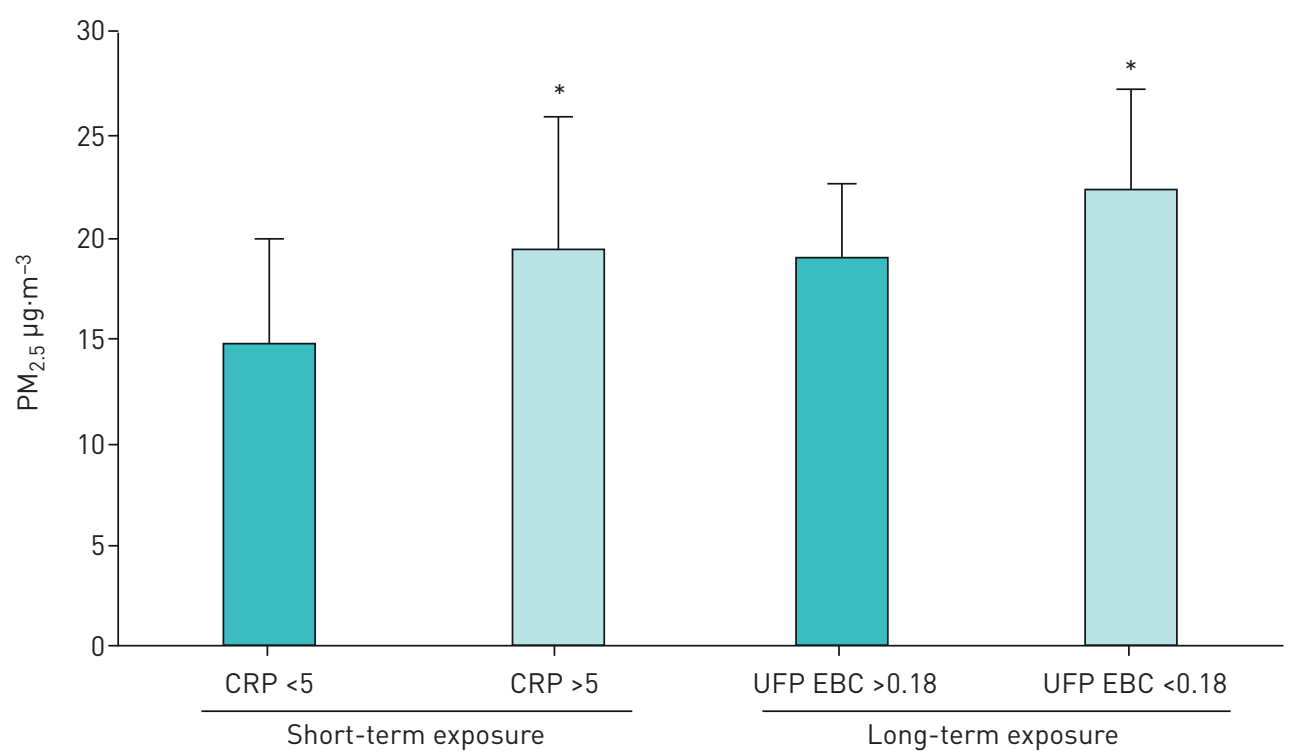

FIGURE 1 CRP in serum level and UFP in EBC content as biomarkers of short- and long-term exposure to $\mathrm{PM}_{2.5}$ in COPD patients. CRP: C-reactive protein $\left(\mathrm{mg} \cdot \mathrm{L}^{-1}\right)$; UFP-EBC: ultrafine particles in exhaled breath condensate $\left(\times 10^{8} \cdot \mathrm{mL}^{-1}\right)$; short-term exposure: average of the previous 3 days; long-term exposure: average of the previous 3 months; *: $p \leqslant 0.05$. 
FIGURE 2 Distribution of the study population according to long-term particulate matter exposure level laverage of previous 3 months). The differences between groups were sex- and age-adjusted. ${ }^{* *}: p \leqslant 0.01$, $* * *: p \leqslant 0.001$.

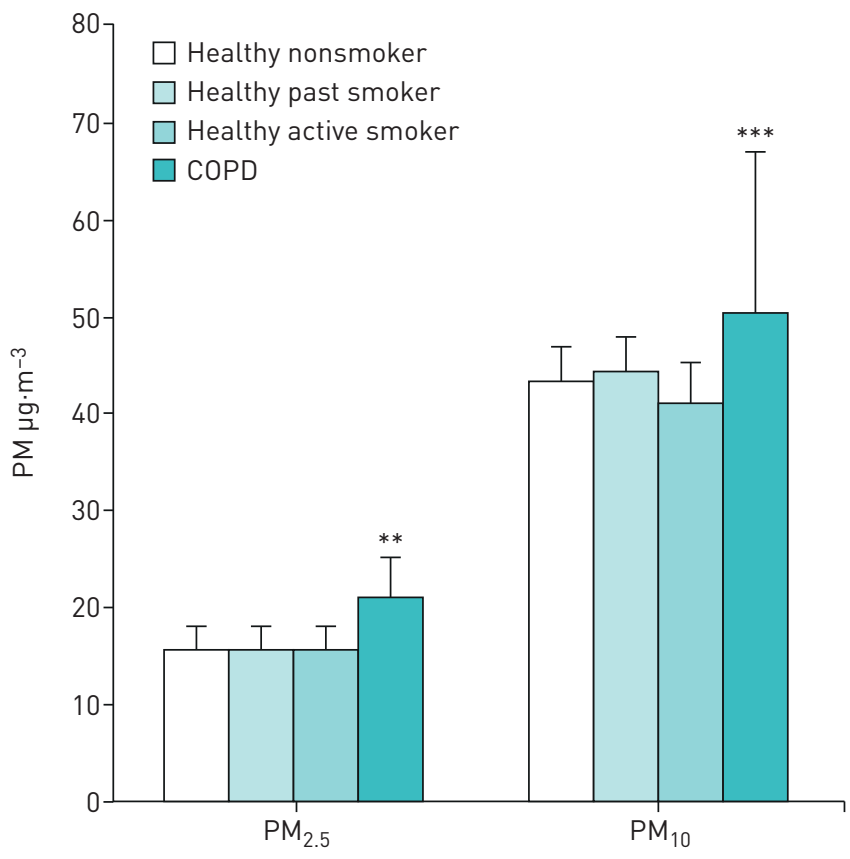

of cadmium by XRF analysis, while other metals such as lead, arsenic, chromium and nickel were present only in levels that were under the limit of detection. Healthy smokers had a higher level of cadmium in EBC compared to both the healthy nonsmokers and the COPD patients (25.2 ppm versus $23.7 \mathrm{ppm}$ and $23.3 \mathrm{ppm}, \mathrm{p}=0.02$ and $\mathrm{p}=0.002$, respectively) (figure $4 \mathrm{a}$ ). In order to clarify whether the cadmium level reflects the content of this metal in the UFPs of EBC samples, we compared these two parameters in COPD patients with those of the healthy smokers. The results are shown in figure $4 \mathrm{~b}$. Subjects with low concentrations of UFP in their EBC also had low cadmium levels in their EBC compared to subjects with high UFP concentrations in their $\mathrm{EBC}$ (22.8 ppm versus $24.2 \mathrm{ppm}, \mathrm{p}=0.004$, figure $4 \mathrm{~b}$.). Moreover, cadmium levels were positively correlated with the UFP concentrations $(r=0.3, p=0.01)$.

\section{Discussion}

We have already shown low UFP concentrations in the inflamed airways of COPD patients [14]. The results here, demonstrate for the first time that the UFPs recovered from smokers' airways have high levels of cadmium, one of the major metals component of cigarette smoke.

Furthermore, biological monitoring of UFP concentration in EBC could be a reliable indicator of high PM exposure levels.
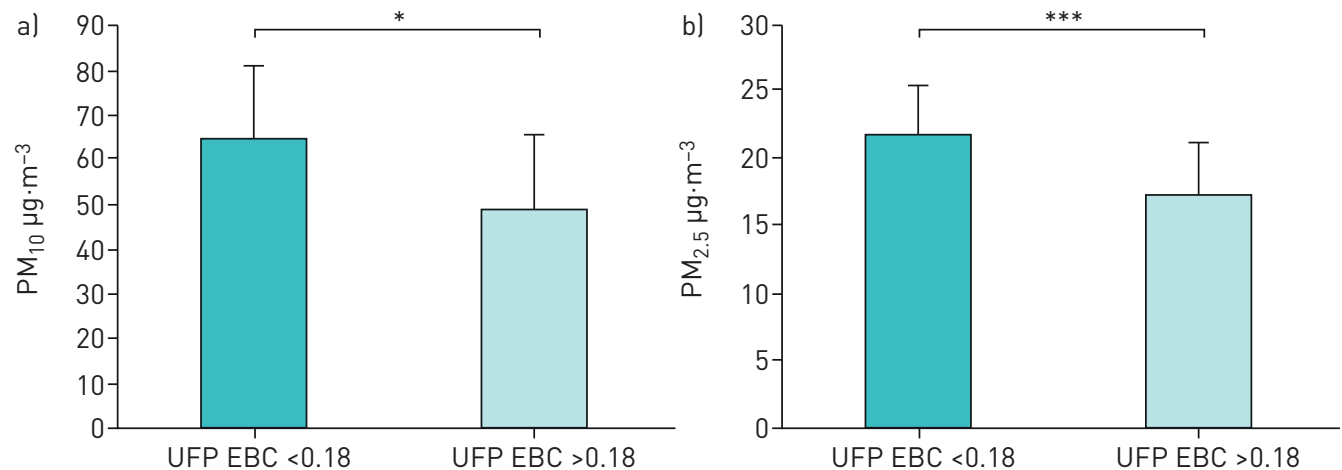

FIGURE 3 Ultrafine particles in exhaled breath condensate content in relation to long-term exposure level (average of previous 3 months) of a) $\mathrm{PM}_{10}$ and b) $\mathrm{PM}_{2.5}$ for the entire study population. UFP-EBC: ultrafine particles in exhaled breath condensate $\left(\times 10^{8} \cdot \mathrm{mL}^{-1}\right) ;{ }^{*}: p \leqslant 0.05, * * *: p \leqslant 0.001$. The $0.18 \times 10^{8} \cdot \mathrm{mL}^{-1}$ cut-off is correlated with disease activity as described in the Methods section. 

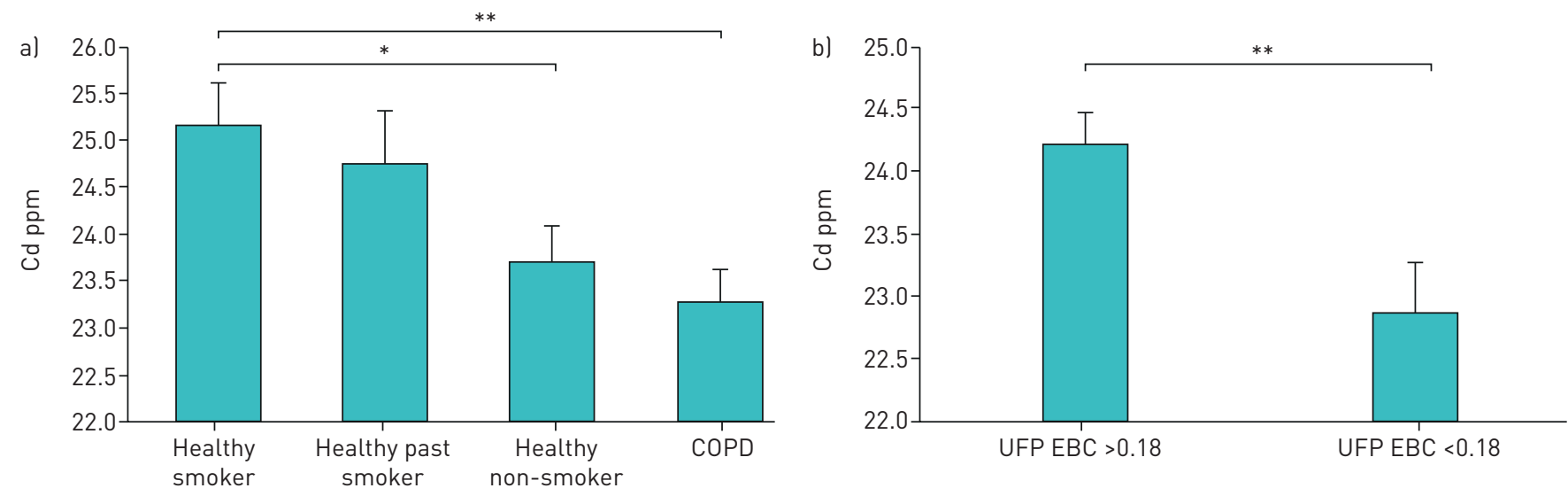

FIGURE 4 Cadmium in EBC levels in a) the entire study population and b) in relation to the UFP in EBC concentrations. Cd: cadmium; UFP-EBC: ultrafine particles in exhaled breath condensate $\left(\times 10^{8} \cdot \mathrm{mL}^{-1}\right) ;{ }^{*}: p \leqslant 0.05, * *: p \leqslant 0.01$.

It is already known that PM exposure is related to increased systemic inflammation markers and decreased lung functions among healthy and COPD populations [22-25]. In our study too, long-term exposure to $\mathrm{PM}_{2.5}$ was associated with high systemic inflammation markers (CRP and LDH) and low $\mathrm{FEV}_{1} \%$ and $D_{\mathrm{LCO}}$ among study populations. $\mathrm{PM}_{2.5}$ and UFP induced inflammation at the alveolar epithelium level [26, 27]. $D_{\text {LCO }}$ measurement is based on exchanged oxygen from the lungs into the blood at the level of the alveolar membrane and vascular endothelium. In this context this both parameters can be correlated. This was previously shown by our group regarding UFPs of artificial stone [12]

The association between environmental PM exposure and increased morbidity and mortality among COPD patients is well established. Indeed, CRP levels in serum were associated with high levels of short-term $\mathrm{PM}_{2.5}$ exposure. CRP levels are elevated rapidly within the first $6-8 \mathrm{~h}$ of the inflammation trigger [28]. The role of high levels of PM exposure in COPD development and progress, however, is inconclusive $[29,30]$. In this context, we found that COPD patients were exposed to a higher level of PM in the long-term measurements compared to healthy controls, independently of the environmental stations that were equally distributed in both groups. The ability of ambient air pollution to induce COPD is biologically conceivable; both ambient PM and cigarette smoke reportedly stimulate common inflammatory pathways in airways [31]. Recent study has shown that $\mathrm{PM}_{2.5}$ enhances apoptosis in cigarette-inflamed bronchial epithelium both in vitro and in vivo [32]. Thus, smokers' exposure to PM may increase their likelihood of developing COPD. Large-scale studies are essential to support our current observation of more COPD patients being present in highly polluted urban areas.

One of the pitfalls in evaluating the relationship between ambient air pollution and COPD is the lack of personal-level monitoring data. Subjects with low concentrations of UFP in EBC $\left(<0.1810^{8} \cdot \mathrm{mL}^{-1}\right)$ were found to be exposed to higher levels of $\mathrm{PM}_{2.5}$ and $\mathrm{PM}_{10}$ than subjects with high UFP concentrations in EBC. These findings are consistent with our previous study that indicate low EBC-UFP concentrations reflect high inflammatory status in airways. COPD patients had lower concentration of UFP in EBC compared to controls. Moreover, frequent exacerbators $(\geqslant 2$ exacerbations per year or $\geqslant 1$ exacerbation resulting in hospitalisation per year) had lower UFP concentrations compared with nonexacerbator patients. Although we did not prove the mechanism responsible for UFP-specific distribution in inflamed airways, the low UFP concentrations in EBC and high in serum of COPD patients compared to controls support our hypothesis that increased epithelial permeability could be the mechanism behind our findings [14].

Increased permeability of the epithelium is part of microcirculatory events that occur during an inflammatory process [33]. We believe that the study population was exposed to several factors that induced inflammation as part of their exposome (e.g. cigarette smoking and air pollution). Specifically, the increase in permeability in the PM-inflamed respiratory epithelium is suggested to allow translocation of UFPs and thus lower their concentration in EBC samples. This hypothesis was supported by the findings in a murine model in which the induction of lung inflammation resulted in a major shift of the UFP pattern towards larger particles, a process which can be explained by translocation of the smaller particles into the circulation [34]. The low UFP concentration in EBC of the inflamed airways could be a potential surveillance tool in patients with chronic lung diseases.

The exposome is considered to represent the total exposures of an individual and their association with health [35]. Given that smoking is a major component in COPD patients' exposomes, we measured 
cigarette-related metal levels in EBC samples and demonstrated high cadmium EBC levels in healthy smokers compared to healthy nonsmokers. Cadmium and lead concentrations in EBC were elevated in healthy smokers compared to healthy nonsmokers. GHIO et al. [36] reported that EBC cadmium and lead concentrations among COPD patients were higher in current smokers compared to past smokers. Among COPD patients, EBC cadmium and lead concentrations were higher in current smokers compared to past smokers [36]. Increased cadmium concentrations was also found in bronchoalveolar lavage (BAL), urine and blood samples of smokers compared to nonsmoker controls [37-39].

Tobacco smoking is a significant source of cadmium exposure among smokers, as tobacco leaves naturally accumulate and concentrate relatively high levels of cadmium. Moreover, due to regulatory activities, occupational exposure to cadmium is currently less common among workers in developed countries [40].

Local toxicity of cadmium in the lungs increases smokers' susceptibility to develop lung diseases, but there are not enough data regarding local deposition of cadmium in lungs [41]. Therefore, measurements of cadmium levels in lung compartments is crucial for a better understanding of the role of cadmium in smoking-related lung diseases. As it is known that the majority of inhaled metals are attached to the UFP surface [42, 43], our findings of low cadmium EBC levels among subjects with low UFP-EBC concentrations $\left(<0.1810^{8} \cdot \mathrm{mL}^{-1}\right)$ may explain the low cadmium levels in EBC of COPD patients compared to healthy smokers. Consistently with our findings, low concentrations of cadmium in BAL (below the limit of detection) were found only in healthy nonsmokers and in smokers with COPD, not in those without COPD [37]. There are several limitations to our study. First, this was a cross-sectional study, precluding the possibility of reproducing the UFP and metal content in EBC in the same subject. Secondly, the subjects' home address was the location of the environmental evaluation, essentially precluding the measurement of exposure during working hours. However, late night and early morning $(\sim 02: 00 \mathrm{~h}$ and $\sim 06: 00 \mathrm{~h})$ are peak hours of air pollution due to meteorological conditions [44], and it was assumed that most people were at home during those hours.

\section{Conclusions}

This is the first report of a correlation between cigarette-related cadmium exposure and the concentrations of UFPs in EBC, which reflect the inflammatory status of airways. Low UFP concentrations in EBC were not only a marker of airway inflammation, but also an indicator of high-level PM exposures. The relationship between the level of PM exposure and UFP-EBC content is innovative and further significant in order to use biological monitoring as part of environmental pollution surveillance. Association between cadmium and UFP content in EBC of COPD patients may reveal the high level of penetration of cadmium and its role in lung toxicity.

Acknowledgments: We would like to express our gratitude and appreciation to Professor Elad Schiff and the Dept of Internal Medicine B at the Bnai-Zion Medical Center for support, mentoring and making this study possible.

Conflict of interest: None declared.

Support statement: This work was supported by the Israel Lung Association.

\section{References}

1 Caplin A, Ghandehari M, Lim C, et al. Advancing environmental exposure assessment science to benefit society. Nat Commun 2019; 10: 1236.

2 Di Q, Wang Y, Zanobetti A, et al. Air Pollution and mortality in the medicare population. N Engl J Med 2017; 376: 2513-2522.

3 Lavigne E, Donelle J, Hatzopoulou M, et al. Spatiotemporal variations in ambient ultrafine particles and the incidence of childhood asthma. Am J Respir Crit Care Med 2019; 199: 1487-1495.

4 WHO. Ambient (outdoor) air quality and health. Published 2018 Date last accessed: March 30, 2019. Date last updated: 2 May, 2018. https://www.who.int/en/news-room/fact-sheets/detail/ambient-.

5 Guan W-J, Zheng X-Y, Chung KF, et al. Impact of air pollution on the burden of chronic respiratory diseases in China: time for urgent action. Lancet 2016; 388: 1939-1951.

6 Parker JD, Kravets N, Vaidyanathan A. Particulate matter air pollution exposure and heart disease mortality risks by race and ethnicity in the United States. Circulation 2018; 137: 1688-1697.

7 McCreanor J, Cullinan P, Nieuwenhuijsen MJ, et al. Respiratory effects of exposure to diesel traffic in persons with asthma. N Engl J Med 2007; 357: 2348-2358.

8 Sinharay R, Gong J, Barratt B, et al. Respiratory and cardiovascular responses to walking down a traffic-polluted road compared with walking in a traffic-free area in participants aged 60 years and older with chronic lung or heart disease and age-matched healthy controls: a randomised, crossover study. Lancet 2018; 391: 339-349.

9 Heinrich J, Schikowski T. COPD patients as vulnerable subpopulation for exposure to ambient air pollution. Curr Environ Heal Reports 2018; 5: 70-76.

10 Hulo S, Radauceanu A, Chérot-Kornobis N, et al. Beryllium in exhaled breath condensate as a biomarker of occupational exposure in a primary aluminum production plant. Int J Hyg Environ Health 2016; 219: 40-47. 
11 Leese E, Morton J, Gardiner PHE, et al. The simultaneous detection of trivalent \& hexavalent chromium in exhaled breath condensate: a feasibility study comparing workers and controls. Int J Hyg Environ Health 2017; 220: 415-423.

12 Ophir N, Shai AB, Alkalay Y, et al. Artificial stone dust-induced functional and inflammatory abnormalities in exposed workers monitored quantitatively by biometrics. ERJ open Res 2016; 2: 00086-2015.

13 Félix PM, Almeida SM, Franco C, et al. The suitability of EBC-Pb as a new biomarker to assess occupational exposure to lead. Int J Environ Health Res 2015; 25: 67-80.

14 Fireman Klein EF, Adir Y, Krencel A, et al. Ultrafine particles in airways: a novel marker of COPD exacerbation risk and inflammatory status. Int J Chron Obstruct Pulmon Dis 2019; 14: 557-564.

15 Li N, Georas S, Alexis N, et al. A work group report on ultrafine particles (American Academy of Allergy, Asthma \& Immunology): why ambient ultrafine and engineered nanoparticles should receive special attention for possible adverse health outcomes in human subjects. J Allergy Clin Immunol 2016; 138: 386-396.

16 Caruso RV, O'Connor RJ, Stephens WE, et al. Toxic metal concentrations in cigarettes obtained from US smokers in 2009: results from the International Tobacco Control (ITC) United States survey cohort. Int J Environ Res Public Health 2013; 11: 202-217.

17 Ashraf MW. Levels of heavy metals in popular cigarette brands and exposure to these metals via smoking. Sci World J 2012; 2012: 1-5.

18 Horváth I, Hunt J, Barnes PJ, et al. Exhaled breath condensate: methodological recommendations and unresolved questions. Eur Respir J 2005; 26: 523-548.

19 Graham, L, Brian, et al. Standardization of Spirometry 2019 Update. An Official American Thoracic Society and European Respiratory Society Technical Statement. AJRCCM 2019; 200: e70-e88. https://doi.org/10.1164/rccm. 201908-1590ST.

20 Jones PW, Harding G, Berry P, et al. Development and first validation of the COPD Assessment Test. Eur Respir J 2009; 34: 648-654.

21 Steinvil A, Fireman E, Kordova-Biezuner L, et al. Environmental air pollution has decremental effects on pulmonary function test parameters up to one week after exposure. Am J Med Sci 2009; 338: 273-279.

22 Dauchet L, Hulo S, Cherot-Kornobis N, et al. Short-term exposure to air pollution: associations with lung function and inflammatory markers in non-smoking, healthy adults. Environ Int 2018; 121: Pt 1, 610-619.

23 Hajat A, Allison M, Diez-Roux AV, et al. Long-term exposure to air pollution and markers of inflammation, coagulation, and endothelial activation: a repeat-measures analysis in the Multi-Ethnic Study of Atherosclerosis (MESA). Epidemiology 2015; 26: 310-320.

$24 \mathrm{Wu} \mathrm{W}$, Jin Y, Carlsten C, et al. Inflammatory health effects of indoor and outdoor particulate matter. J Allergy Clin Immunol 2018; 141: 833-844.

25 Adam M, Schikowski T, Carsin AE, et al. Adult lung function and long-term air pollution exposure. ESCAPE: a multicentre cohort study and meta-analysis. Eur Respir J 2015; 45: 38-50.

26 Yang J, Chen Y, Yu Z, et al. The influence of $\mathrm{PM}_{2.5}$ on lung injury and cytokines in mice. Exp Ther Med 2019; 18 2503-2511.

27 Leikauf GD, Kim S-H, Jang A-S. Mechanisms of ultrafine particle-induced respiratory health effects. Exp Mol Med 2020; 52: 329-337.

28 World Health Organization. VMNIS | Vitamin and Mineral Nutrition Information System C-Reactive Protein Concentrations as a Marker of Inflammation or Infection for Interpreting Biomarkers of Micronutrient Status. http:// apps.who.int/iris/bitstream/10665/133708/1/WHO Date last accessed: April 16, 2019. Date last updated: 2014

29 Schikowski T, Mills IC, Anderson HR, et al. Ambient air pollution: a cause of COPD? Eur Respir J 2014; 43 250-263.

30 Weichenthal S, Bai L, Hatzopoulou M, et al. Long-term exposure to ambient ultrafine particles and respiratory disease incidence in in Toronto, Canada: a cohort study. Environ Heal 2017; 16: 64.

31 Ling SH, van Eeden SF. Particulate matter air pollution exposure: role in the development and exacerbation of chronic obstructive pulmonary disease. Int J Chron Obstruct Pulmon Dis 2009; 4: 233-243.

32 Zhou T, Hu Y, Wang Y, et al. Fine particulate matter $\left(\mathrm{PM}_{2.5}\right)$ aggravates apoptosis of cigarette-inflamed bronchial epithelium in vivo and vitro. Environ Pollut 2019; 248: 1-9.

33 Chen $\mathrm{L}$, Deng $\mathrm{H}$, Cui $\mathrm{H}$, et al. Inflammatory responses and inflammation-associated diseases in organs. Oncotarget 2018; 9: 7204-7218.

34 Bar-Shai A, Alcalay Y, Sagiv A, et al. Fingerprint of lung fluid ultrafine particles, a novel marker of acute lung inflammation. Respiration 2015; 90: 74-84.

35 Wild CP. The exposome: from concept to utility. Int J Epidemiol 2012; 41: 24-32.

36 Ghio AJ, Madden MC, Esther CR Jr. Transition and post-transition metals in exhaled breath condensate. J Breath Res 2018; 12: 027112.

37 Sundblad B-M, Ji J, Levänen B, et al. Extracellular cadmium in the bronchoalveolar space of long-term tobacco smokers with and without COPD and its association with inflammation. Int J COPD 2016; 11: 1005-1013.

38 Adams S V, Newcomb PA. Cadmium blood and urine concentrations as measures of exposure: NHANES 1999-2010. J Expo Sci Environ Epidemiol 2014; 24: 163-170.

39 Mannino DM, Holguin F, Greves HM, et al. Urinary cadmium levels predict lower lung function in current and former smokers: data from the Third National Health and Nutrition Examination Survey. Thorax 2004; 59: 194-198.

40 International Cadmium Association. All the information on Cadmium - Level of cadmium in the environment. www.cadmium.org/environment/level-of-cadmium-in-the-environment Date last accessed: April 13, 2020. Date last updated: 2010

41 Ganguly K, Levänen B, Palmberg L, et al. Cadmium in tobacco smokers: a neglected link to lung disease? Eur Respir Rev 2018; 27: 1-8.

42 Chen LC, Lippmann M. Effects of metals within ambient air particulate matter (PM) on human health. Inhal Toxicol 2009; 21: 1-31.

43 Donaldson K, Stone V, Cloutera A, et al. Ultrafine particles. Occup Environ Med 2001; 58: 211-216.

44 Cohen P, Potchter O, Schnell I. A methodological approach to the environmental quantitative assessment of urban parks. Appl Geogr 2014; 48: 87-101. 